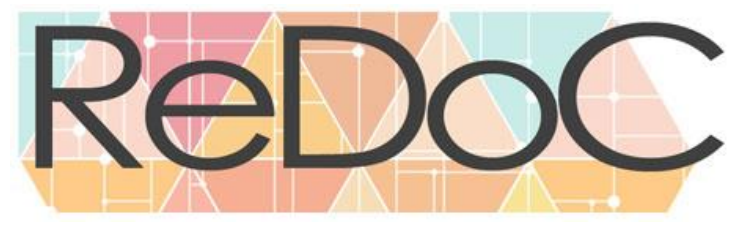

Revista Docência e Cibercultura

\title{
INTERVENÇÃO DIDÁTICA COM GAMIFICAÇÃO: \\ RELATO DE DUAS EXPERIÊNCIAS EM INSTITUIÇÕES PÚBLICAS
}

TEACHING INTERVENTION WITH GAMIFICATION:

REPORT OF TWO EXPERIENCES IN PUBLIC INSTITUTIONS

INTERVENCIÓN DOCENTE COM GAMIFICACIÓN:

INFORME DE DOS EXPERIENCIAS EM INSTITUCIONES PÚBLICAS

Keite Silva de $\mathrm{Melo}^{2}$

Simone Regina de Oliveira Ribeiro ${ }^{3}$

\begin{abstract}
RESUMO
O presente relato tem por objetivo apresentar possibilidades de práticas pedagógicas gamificadas, em distintos segmentos de ensino. Uma prática foi desenvolvida junto a alunos do ensino fundamental de uma rede municipal na Baixada Fluminense e a outra, no curso de Pedagogia, em uma instituição de ensino superior da rede estadual. Nas duas experiências, buscou-se adotar uma mediação didática ancorada com a produção autoral discente, usando, para isso, o potencial das tecnologias digitais na produção de jogos. Entendemos que é possível conciliar práticas inovadoras e criativas com outras manifestações políticas, de necessário resgate da carreira docente e das instituições públicas. A prática docente intencional, que inclui jogos como apoio ao ensino, instiga, por meio de desafios, a mobilização das operações internas, seja jogando ou levando os alunos a produzirem novos jogos. A ludicidade mobiliza os sujeitos, engajando-os em atividades que demandam maior capacidade de abstração e desafios complexos, que, de outra forma, poderiam não ter a mesma adesão e compreensão. A maior parte dos jogos foi desenvolvida sem a necessidade de acesso à rede, mas essa ação docente, apesar de investir na criatividade e autoria, não exclui a urgência em se denunciar a exclusão digital vivenciada por boa parte das instituições educacionais públicas, principalmente por estarmos vivendo em uma era de mobilidade e crescente ubiquidade. Espera-se, com isso, inspirar ações e formações para a adoção do lúdico na educação, reconhecendo o potencial das tecnologias off-line, que são as tecnologias garantidas na maior parte dos espaços educacionais.
\end{abstract}

PALAVRAS-CHAVE: Práticas docentes. Autoria discente. Produção de jogos. Ludicidade na educação.

Gamificação.

\section{ABSTRACT}

The aim of this paper is to present possibilities of gamified pedagogical practices in two different teaching segments. One practice was developed with elementary school students from a municipal educational system in Baixada Fluminense, and the other one in the Pedagogy course of a state higher education institution. In both experiments, our objective was to adopt a didactic mediation based on the student authorship production, using, for this, the potential of digital technologies in the production of games. We believe that it is possible to reconcile innovative and creative practices with other political manifestations, trying to come up teaching career

Submetido em: 26/08/2019 - Aceito em: 11/04/2019 - Publicado em: 28/12/2019.

${ }^{2}$ Doutora em Educação pela PUC-Rio, professora do ensino superior do ISERJ/FAETEC e professora da rede municipal de Educação de Duque de Caxias.

${ }^{3}$ Mestra em Letras e Ciências Humanas pela UNIGRANRIO, atua como Técnico em Assuntos Educacionais no CEFET/RJ. É professora da rede municipal de Educação de Duque de Caxias e professora-tutora a distância das Licenciaturas UERJ/CEDERJ. 


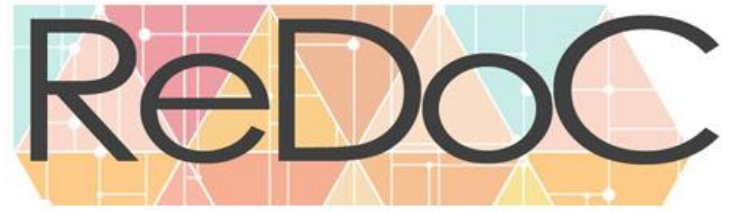

Revista Docência e Cibercultura

and public institutions. Intentional teaching practice, like games that support teaching, instigates the mobilization of internal operations through challenges, whether by playing games or leading students to produce new games. Playfulness stimulates subjects, engaging them in activities that demand greater capacity for abstraction and complex challenges, which, on the other hand, might not have the same adhesion and understanding. Most part of games was developed without the necessity of network access, but this teaching action, despite investing in creativity and authorship, does not exclude the urgency to denounce the digital exclusion experienced by most public educational institutions, especially because we are living in a period of mobility and expansion of ubiquity. In conclusion, we hope that both experiences will be able to inspire actions and training for the adoption of the playful in education, recognizing the potential of offline technologies, which are guaranteed in most part of educational spaces.

KEYWORDS: Teaching Practices. Student Authorship. Game Production. Playfulness in Education.

Gamification.

\section{RESUMEN}

El presente informe tiene como objetivo presentar las posibilidades de las prácticas didácticas gamificadas en diferentes segmentos de enseñanza. Una práctica se desarrolló con estudiantes de primaria de una red municipal en la Baixada Fluminense y la otra, en el curso de Pedagogía en una institución de educación superior de la red estatal. En ambos experimentos buscamos adoptar una mediación didáctica anclada a la producción de autor del estudiante, utilizando para ello el potencial de las tecnologías digitales de información y comunicación en la producción de juegos. Entendemos que es posible conciliar prácticas innovadoras y creativas, con otras manifestaciones políticas, del necesario rescate de la carrera docente y de las instituciones públicas. La práctica docente intencional, que incluye juegos para apoyar la enseñanza, estimula a través de los desafíos la movilización de operaciones internas, ya sea jugando juegos o guiando a los estudiantes a producir juegos nuevos. El juego moviliza a los sujetos, involucrándolos en actividades que exigen una mayor capacidad de abstracción y desafíos complejos, que de otro modo podrían no tener la misma adhesión y comprensión. La mayoría de los juegos se desarrollaron sin necesidad de acceso a la red, pero esta acción de enseñanza, a pesar de invertir en creatividad y autoría, no excluye la urgencia de denunciar la exclusión digital experimentada por la mayoría de instituciones educativas públicas, principalmente porque vivimos en una era de movilidad y ubicuidad creciente. Espera inspirar acciones y capacitación para la adopción de la educación lúdica, reconociendo el potencial de las tecnologías fuera de línea y las tecnologías disponibles en la mayoría de los espacios educativos.

PALABRAS CLAVE: Prácticas de enseñanza. Autoría estudiantil. Producción de juegos. Juguetería en la educación. Gamificación.

\section{INTRODUÇÃO}

Neste país com dimensões continentais, embora haja grande distinção em termos de acesso a uma infraestrutura condizente com a inclusão digital dos estudantes dos diversos segmentos, o problema de apropriação das tecnologias nas escolas vem se assemelhando nos diversos estados. Se buscarmos exemplos de apropriação que incluam a ludicidade com tecnologias na produção autoral de jogos por alunos, pode haver ainda mais dificuldade em localizar ações que inspirem novas produções autorais com esta abordagem, ou mesmo, apropriações remixadas, próprias da prática docente. 
$\mathrm{Na}$ apresentação dos principais resultados da pesquisa TIC Educação de $2017^{4}$ (CETIC.br, 2018), quanto ao uso de tecnologias por professores e alunos nas áreas urbanas, $45 \%$ dos professores afirmam ter trabalhado com jogos educativos com os seus alunos. $26 \%$ destes professores fizeram esse trabalho com o uso de tecnologias. Embora esse número ainda seja pequeno, já é um prenúncio de adoção das tecnologias para educação, com uma perspectiva inovadora e ancorada na ludicidade.

Apesar disso, este valor inclui escolas públicas e particulares que, sabemos, possuem recursos completamente distintos. Quando observamos os dados apenas das escolas públicas, a apropriação das tecnologias que mais se destaca é a criação e gestão de página ou perfil em redes sociais, ação adotada por pelo menos $67 \%$ das escolas. Esse número é expressivo e aponta para busca por visibilidade e diálogo com a comunidade, já que a maior parte das páginas em redes sociais está aberta à recepção de comentários. Apesar disso, não se trata de uma ação que torna o aluno protagonista e autor de produções voltadas para melhor compreensão dos conceitos científicos trabalhados pelos docentes, com apoio das tecnologias.

Em recente pesquisa, a CETIC.br (2018) revelou que 55\% dos alunos de escola pública jogam jogos educativos, enquanto $11 \%$ dos professores usuários de internet destas escolas, desenvolvem projetos com alunos, usando tecnologias. Mas os números que nos chamam mais a atenção são: apenas 3\% dos professores criaram sites, páginas ou blogs com os alunos, e $1 \%$ dos professores criou um jogo de computador ou aplicativo com a participação dos seus alunos. Nota-se a ausência de práticas didáticas que incluam a criatividade e autoria dos alunos, reconhecendo-se que são praticantes da cultura dos jogos e estariam a priori, instigados por desenvolverem produções mais inovadoras para responder às proposições didáticas docentes.

Qual o fenômeno que poderia explicar esse número (1\%) tão reduzido? De tão ínfimo, alarma todos os profissionais que pesquisam e praticam docência com apoio do lúdico na educação. Como contribuir para que haja mais iniciativas de adoção do potencial das tecnologias digitais da informação e comunicação (TDIC) para produção de jogos com e por alunos de instituições públicas? Neste trabalho, trazemos dois relatos de práticas docentes em instituições públicas, que se voltaram a essa ação. Uma experiência ocorreu na rede municipal

\footnotetext{
${ }^{4}$ Pesquisa realizada entre agosto e dezembro de 2017, com "escolas públicas (exceto federais) e privadas com turmas de $5^{\circ}$ ano ou $9^{\circ}$ ano do Ensino Fundamental ou $2^{\circ}$ ano do Ensino Médio". A amostra realizada para esta pesquisa contou com "957 escolas, 957 diretores, 884 coordenadores pedagógicos, 1.015 professores (língua portuguesa, matemática e de anos iniciais do Ensino Fundamental) e 10.866 alunos das turmas de interesse". (CETIC.br, 2018, p. 5).
} 


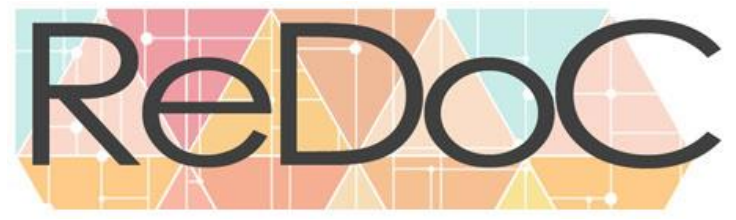

\section{Revista Docência e Cibercultura}

de Duque de Caxias, com crianças dos anos iniciais do ensino fundamental, nos anos de 2014 e 2015, e foi desenvolvida pela segunda autora deste artigo; e a outra experiência ocorreu no curso de Pedagogia, do Instituto Superior de Educação do Rio de Janeiro, desenvolvida pela primeira autora. Nossa intenção com a reunião destes relatos é apresentar possibilidades de práticas didáticas, que inspirem ações e formações docentes para adoção do lúdico na educação, com o potencial das TDIC, nos diversos segmentos de instituições públicas de ensino.

\section{Gamificação na Educação e mediação didática}

$\mathrm{O}$ ato de brincar é muito antigo e abrange todas as faixas etárias. Crianças, jovens e adultos são naturalmente atraídos por atividades que envolvam a ludicidade, por isso, justifica-se o fato de diferentes estudos e investigações direcionados ao lúdico, às questões didáticas relacionadas ao processo de ensino-aprendizagem e, mais recentemente, à gamificação. Segundo Carvalho (2017, p. 131), “o termo gamification tem sido aportuguesado para gamificação, evidenciando o vínculo ao termo game em inglês. Há quem prefira o termo ludificação, tendo por base a palavra latina ludus (jogo).”. A gamificação seria a ação de transformar em jogos, cenários, conteúdos e dinâmicas, que, a priori, não teriam essa abordagem ou formato. A proposta de gamificar atividades na escola ou universidade teria por intenção envolver os alunos, engajando-os e estimulando oportunidades de aprendizagem por meio de desafios ou problematizações.

A literatura conceitua o lúdico como uma categoria que pode envolver brincadeiras, jogos, brinquedos, entre outras situações de divertimento e está diretamente ligada à aprendizagem. De acordo com Santos (2010), a palavra "lúdico" vem do latim ludus e significa brincar, incluindo os jogos, brinquedos e divertimentos, além de se relacionar ao comportamento de jogar e divertir-se; afirma a função educativa do jogo que oportuniza a aprendizagem do indivíduo, seu saber, seu conhecimento e sua compreensão de mundo. Para Matos et al. (2010), o lúdico é caracterizado como uma categoria geral na qual estão inseridas todas as atividades caracterizadas como jogos, brinquedos e brincadeiras. Lévy (1993) lembra que as sociedades orais primárias, comunidades anteriores ao advento da escrita, utilizavam recursos lúdicos com grande carga emotiva, como técnicas para acionar a memória de longo prazo, transmitindo as suas representações e conhecimento acumulado para os seus descendentes, por meio de rimas, ritmos, poemas, cantos, dança, rituais, narrativas, entre outros. Huizinga (2000, p. 32), ao definir o conceito de ludicidade, enumera conceitos como "desafio, perigo, competição, [...] perigo, risco, sorte, temeridade" como próprios de muitos formatos de jogos, ou seja, nem todos os jogos atuam com a sensação de alegria e prazer a todo o momento, mas 
podem acionar seriedade, incerteza, tensão, paciência, esforço, concentração, resistência e imersão, em dados momentos ou, mesmo, na maior parte do tempo. Mas a busca pela vitória, conquista, satisfação, estima, prestígio, e autoaprovação fundam a motivação dos sujeitos que buscam jogos sérios, ainda que tenham que lidar com sensações que poderiam ser consideradas negativas. Mesmo essas fazem parte do lúdico que permeia a imersão no jogo e é nesse sentido que os jogadores, ao buscarem a vitória, lidam com o peso da seriedade própria da busca por superação.

Para a abordagem histórico-cultural, é no jogo que se concentra a atividade dominante da criança, em dada fase do desenvolvimento. A atividade, segundo Leontiev (1978, p. 13), é "um processo que é eliciado e dirigido por um motivo - aquele no qual uma ou outra necessidade é objetivada. Em outras palavras: por trás da relação entre atividades, há uma relação entre motivos". Segundo este autor, que prosseguiu os estudos de Vygotsky, pode haver mais de uma atividade em ação no sujeito, mas é a atividade dominante que leva ao "aparecimento na sua consciência de novos fins e a formação de novas ações correspondentes.” (LEONTIEV, 2004, p. 331).

Os processos psíquicos estão (re)organizados na atividade dominante, onde ocorrem "as mudanças psicológicas fundamentais da personalidade" (LEONTIEV, 2004, p. 311). No caso da criança, é por meio do jogo, enquanto atividade dominante, que se iniciam a imaginação, o raciocínio abstrato e a aprendizagem. Além disso, segundo Nascimento, Araújo e Migueis (2016), o jogo aproxima a criança do mundo, ajudando-a a se apropriar da realidade e, com ela, interagir.

Os recursos lúdicos desencadeiam a predisposição natural do ser humano para compreender melhor os conteúdos. Além disso, interferem nas esferas motoras, cognitivas e afetivas dos indivíduos, potencializando a aprendizagem, o desenvolvimento mental e social da pessoa que brinca e joga durante o processo de aprendizagem (CABRERA; SALVI, 2005).

Entendemos que os jogos educativos, quando planejados e articulados dentro de uma prática didática consistente, favorecem e potencializam a aprendizagem dos estudantes, sejam eles digitais ou não. Cruz e Castro (2014, p.5) definem os jogos educativos e apontam seu potencial para o ensino:

Jogos educativos têm a finalidade de promover o ensinamento lúdico de alguma atividade e ou disciplina. Assim como os jogos tradicionais podem entreter e ensinar o jovem, os jogos digitais educativos também possuem esse potencial. No jogo tradicional, além da experiência proveniente da prática do jogo, obtém-se uma experiência social enriquecedora, pois, ao participar de um jogo, o jovem torna-se 


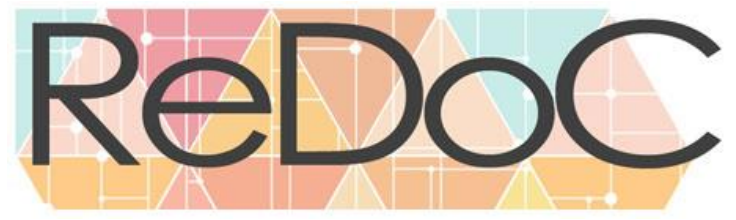

Revista Docência e Cibercultura

mais sociável, de modo que mesmo indivíduos mais tímidos desfrutem experiências enriquecedoras. (CRUZ; CASTRO, 2014, p. 5).

Além de sinalizar a importância dos jogos educativos, os mesmos autores (ibidem, p. 5) destacam algumas habilidades que devem ser contempladas para que os jogos sejam úteis ao processo de aprendizagem:

Para que sejam realmente viáveis e úteis no processo de ensino-aprendizagem, os jogos educativos (digitais ou não) devem estimular o pensamento crítico, o uso de múltiplas representações, a capacidade de resolver problemas, o trabalho em grupo e o desenvolvimento das habilidades de comunicação. Além disso, sua concepção deve permitir e valorizar o uso da criatividade e experimentação. (CRUZ; CASTRO, 2014, p. 5).

Os jogos, inclusive os digitais, exercem "influência sobre o desenvolvimento psíquico da criança e sobre a formação de sua personalidade" (FACCI, 2004, p. 69). Sendo assim, as suas características, quando aplicadas ao processo de ensino-aprendizagem, motivam o desafio, a fantasia e a curiosidade, propiciando oportunidades para o aluno usar lógica, raciocínio e habilidades de organização para resolver problemas de maneira mais interessante do que seriam expostos em um exercício comum no papel, por exemplo. Um jogo simples pode ensinar várias habilidades e conceitos, fundamentando o desenvolvimento de novas habilidades cognitivas (FALKEMBACH; GELLER; SILVEIRA, 2006).

Os jogos ou games possuem a motivação como principal característica para a aprendizagem (SANTAELLA, 2013), aliando diversão, aprendizagem por descoberta e levando o jogador à "prontidão para tomada de decisões". Também é possível, quando adotada a colaboração na realização ou implementação dos jogos, que alguns comportamentos, como respeito ao posicionamento do outro, lidar com alguma frustração própria da falta de experiência com processos democráticos, reconhecer e fortalecer a habilidade de outrem para a equipe concluir a atividade coletiva em que estão engajados, entre outros, possam ser desenvolvidos com o auxílio do professor ou colegas mais experientes (VYGOTSKY, 2003).

Com o uso do computador chamado por Levy (1993) de interface cognitiva, por Valente (1993) de ferramenta pedagógica, por Gadotti (2000) de recurso tecnológico, novos desafios são postos diante da escola. O estilo digital "engendra novos comportamentos, novas racionalidades, novos estímulos perceptivos" (PROVENZANO; WALDHELM, 2009, p. 23). Para além do computador, que está geralmente fixo a um determinado local, encontramos os dispositivos móveis (celulares, smartphones, tablets), dentre eles destacamos a potencialidade do smartphone, que é bastante popular entre os estudantes, além de garantir conexão a todo tempo e lugar, desde que esteja com acesso à Internet. Esses dispositivos culturais podem 
favorecer a prática docente em diferentes espaços, apoiando o planejamento didático e a implementação de aulas mais condizentes com os desafios do nosso tempo.

A prática didática interessada pelo trabalho com jogos não pode estar centrada nas práticas tradicionais ou tecnicistas de ensino. Não basta transferir práticas de aprendizagem mecânica para um contexto de jogos, nem lançar mão dos mais modernos equipamentos eletrônicos ou digitais sem a criticidade e a problematização por parte dos docentes. A transformação das práticas didáticas que utilizam jogos e games é fundamental para que o contexto lúdico contemple desafios interessantes e possíveis para os estudantes. A prática didática com jogos exige que metodologias mais ativas e interativas sejam utilizadas para que o aluno se envolva de forma imersiva durante a construção do conhecimento.

Portanto, a prática docente intencional, que inclui jogos como apoio ao ensino, instiga a mobilização das operações internas, seja jogando, ou levando os alunos a produzirem novos jogos por meio de desafios. Esta seria uma proposta de mediação didática ancorada com a produção autoral discente. Para Libâneo (2018, p. 39-40), os processos de mediação didática

[...] têm como suporte a unidade entre o aprender e o ensinar, numa relação necessariamente mútua, em que o aluno é orientado em sua atividade autônoma por adultos e colegas visando a apropriação dos produtos da cultura, da ciência, da arte, de modo geral, da experiência humana social e historicamente acumulada. A didática articula a lógica dos saberes a ensinar (dimensão epistemológica), a lógica dos modos de aprender (dimensão psicopedagógica) e a lógica das relações entre práticas socioculturais e ensino (dimensão sociocultural e institucional), por onde se requer sua dependência da epistemologia das disciplinas, da relação conteúdos/métodos/metodologias de ensino, dos processos de aprendizagem e desenvolvimento, das interfaces com as práticas socioculturais.

Neste sentido, a formação de professores deve amparar-se pela crítica e pela imersão junto aos artefatos mediadores que produzem a cultura. Não é possível formar sem imersão, sem a experimentação da cultura a ser compreendida, em toda a sua complexidade. No caso deste relato, a imersão se concretiza na produção de jogos para e com alunos, inclusive na formação inicial de professores, almejando a articulação entre discurso e prática, além de buscar a superação do excesso de discurso que esconde as práticas (NÓVOA, 1999). Outro pressuposto que assumimos em nossas ações é este proposto por Sacristán (1995, p. 74) de que o professor é um profissional que pode adotar "o seu conhecimento e a sua experiência para se desenvolver em contextos pedagógicos práticos preexistentes”. Sendo assim, ao 


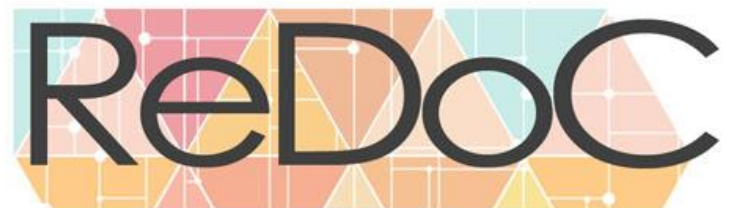

Revista Docência e Cibercultura

imergir na cultura digital, habitando-a, esse contato in loco potencializa e desafia as elaborações coletivas, como as que trazemos neste trabalho.

Concordamos com os pesquisadores Melo e Oliveira (2018) e Oliveira e Lima, (2017), que denunciam que a autonomia docente para mediações didáticas inovadoras não está garantida em todos os espaços e tempos. Oliveira e Lima (2017) compreendem que há uma quebra da produção criativa dos professores, pois não estão garantidas as condições materiais para tal ação. Os obstáculos cotidianos de ordens macro/meso/micro, que atravessam a mediação didática de professores de instituições públicas, são notórios e eventualmente desencadeiam a repetição, alienação na fragmentação da atividade dominante (LEONTIEV, 2004), entre outras consequências.

Apesar disso, acreditamos que o potencial criativo constitui todos os sujeitos, e o percurso sócio-histórico construído por cada um funda a constituição da sua consciência intra e intersubjetiva, podendo levá-los a ter (re)ações distintas ao se deparar com um cenário hostil. Há os que, sem parceria e interação com os pares, não encontram forças, para reconheceremse como criativos e adotar esta potência para e com os seus alunos. Também há os que, por não se conformarem com este mesmo cenário, encontram na criatividade o fator impulsionador para busca de mudança, mesmo com barreiras institucionais ou burocráticas, desde que estas sejam transponíveis.

Não nos colocamos na posição ingênua de quem nega as hostilidades que afrontam a carreira docente $^{5}$ e as instituições educacionais públicas. Buscamos no fazer docente e na pesquisa comprometida com a formação para mudança formas outras de resistência política para garantir e usufruir da educação de qualidade enquanto bem comum e democrático. Entendemos que é possível conciliar práticas inovadoras e criativas, com outras manifestações políticas, de necessário resgate da carreira docente e das instituições públicas. Com isso, o presente relato de práticas mediadoras busca oferecer aos professores, que, por diversos motivos, estão vivenciando momentos de pausa em sua ação criadora na mediação didática, uma inspiração para ação e transgressão desta pausa, e aos professores que acionam uma mediação didática criativa, um diálogo que corrobore com suas escolhas cotidianas.

\section{Gamificação nos anos iniciais}

\footnotetext{
${ }^{5}$ Enquanto redigíamos esse artigo, com o relato de nossas práticas mediadoras, também estávamos sofrendo de um dos maiores problemas que impactam na mediação didática criativa: os atrasos de salários na rede municipal de Duque de Caxias, onde as autoras atuam como professoras. Além deste problema, lidamos com um cenário hostil de congelamento de investimentos na Educação, além das perdas de direitos históricos no magistério, conquistados com muita luta e enfrentamento na referida rede, achatando os salários, que não estão com a frequência garantida desde o final de 2016.
} 
O presente relato retrata uma prática que foi desenvolvida nos anos iniciais de escolaridade na Escola Municipal Wanda Gomes Soares, em Duque de Caxias, no Rio de Janeiro, durante os anos de 2014 e $2015^{6}$. A escola atendia, na ocasião, 12 turmas (seis em cada turno). As turmas eram atendidas uma vez por semana na sala de informática durante 50 minutos.

A tessitura do texto apresenta a proposta didática e metodológica do trabalho, com uma parceria entre os professores regentes e a professora da sala de informática educativa, com exemplos de atividades práticas desenvolvidas pelos estudantes.

A prática aplicada buscou ancorar-se em uma ação docente significativa, reflexiva e crítica, adotando a gamificação. Nas práticas cotidianas destes professores de informática educativa, sempre que possível, investe-se em uma abordagem interdisciplinar, conciliando ensino à pesquisa e projetos.

A atuação do professor de tecnologias envolve a utilização de diferentes recursos tecnológicos como fotografia, cinema, rádio, televisão, jogos, jornais, revistas, brincadeiras, além do computador, que é predominante nas aulas.

A professora utilizou games disponíveis no sistema operacional customizado para o município, que estava instalado nos computadores, o Lineduc ${ }^{7}$. Também estão disponíveis jogos offline baseados no software livre, dentre eles, softwares de autoria para produção de outros jogos. Nesse aspecto, está garantida a autoria do profissional quando elabora e produz, por exemplo, jogos usando Impress, disponível no pacote Office. O Impress é um editor de apresentações do software livre ou o $\mathrm{Jclic}^{8}$, ferramenta simples para a gestão de atividades educativas de download gratuito, além de outras ferramentas offline.

Importante ressaltar que a escolha pela mediação didática com jogos offline justifica-se pelo fato de a escola não possuir uma rede de acesso à Internet que sustente a ação simultânea dos estudantes, nos computadores da sala de informática. Portanto, os jogos precisam ser desenvolvidos e implementados sem requerer acesso à Rede.

\footnotetext{
${ }^{6}$ Importante destacar que, por motivos de mudança na política educacional do município citado, a professora não atuou mais como mediadora de tecnologia a partir de 2015.

${ }^{7}$ Versão própria da rede municipal para o sistema operacional Linux Educacional.

${ }^{8}$ Disponível em: https://jclic.br.uptodown.com/windows
} 


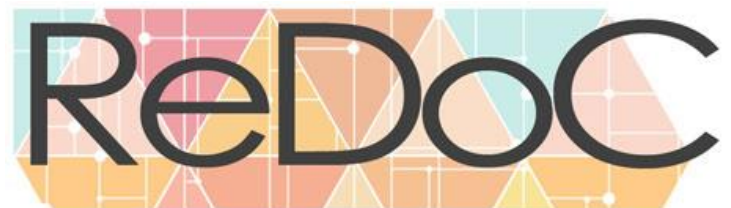

Revista Docência e Cibercultura

O objetivo da ação pedagógica da professora foi desenvolver habilidades e competências em que os estudantes expressassem opiniões, ideias, pensamentos e sentimentos por meio de uma relação dialógica com o interlocutor adulto, seus pares e a tecnologia. Partimos da premissa de que toda relação de ensino e aprendizagem na sala de informática deve envolver a troca de saberes num ambiente lúdico, com jogos digitais ou não.

Durante as atividades, os estudantes se envolvem nos games e colocam em prática o conhecimento acumulado, aprendendo novos conceitos e ampliando conhecimentos em trocas constantes. Nas atividades com os jogos, geralmente, não há espaço para longas cópias, memorização ou reprodução de conteúdos sem significado, ou seja, o objetivo não é a reprodução, mas a construção do próprio conhecimento.

Em geral, o trabalho é desenvolvido em duplas, trios e até grupos de estudantes, quase nunca individualmente. A organização em parceria ocorre por, pelo menos, dois fatores: o primeiro é operacional e logístico, pois o laboratório não possui um computador para cada aluno; o segundo, não menos importante, é o fator pedagógico, por acreditarmos que o trabalho em parceria pode potencializar o desenvolvimento e a construção de novos conceitos de acordo Vygotsky (2003) e seu estudo da Zona de Desenvolvimento Proximal (ZDP). Para Vygotsky, “a zona de desenvolvimento proximal define aquelas funções que ainda não amadureceram, mas que estão em processo de maturação, funções que amadurecerão, mas que estão presentemente em estado embrionário" (2003, p. 98).

Por estarem em estágio embrionário, é preciso que sejam desenvolvidas, que haja um estímulo para que tornem o conhecimento potencial do estudante em conhecimento real. A ZDP se encontra, justamente, entre o conhecimento potencial e o real. Para o autor, o resultado entre as trocas, as hipóteses, as dúvidas entre os estudantes e seus pares desencadeia novas aprendizagens. É por meio dos conflitos cognitivos e das trocas entre os pares que os estudantes avançam e os jogos favorecem sensivelmente tal processo.

A organização da sequência didática dos temas e conteúdos está ancorada na troca de informações entre os professores regentes (das turmas) e a professora mediadora de tecnologias em um trabalho de parceria. Para articular a comunicação e viabilizar o planejamento desta parceria, cada professor regente preenchia mensalmente um formulário para organizar as estratégias didáticas e conteúdos trabalhados a cada semana. A partir deste, a mediadora planejava a aula, selecionava jogos com desafios adequados ao conteúdo e nível de ensino da turma. 


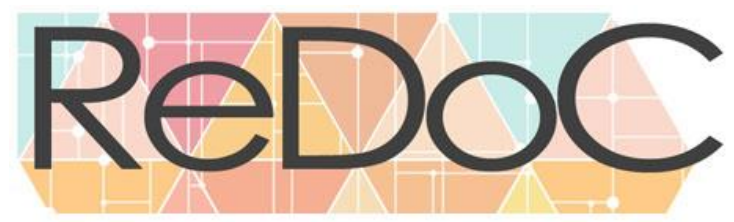

Revista Docência e Cibercultura

No ano de 2015, a escola desenvolveu o projeto “Água: sabendo usar não vai faltar”. Todas as turmas foram envolvidas e a sala de informática também contemplou o tema. Os alunos do segundo ano, por exemplo, trabalharam o ciclo da água. Como proposta elas assistiram ao vídeo Clarinha e o ciclo da água', a seguir resolveram desafios nos jogos offline denominados Gcomprix, uma suíte educacional de alta qualidade, com diferentes jogos para crianças com idade entre dois e dez anos.

Com as turmas de quinto ano do ensino fundamental, foram desenvolvidas atividades de experiência para trabalhar conceitos diversos, como, por exemplo, a densidade da água. Para tanto, os estudantes deveriam entender o conceito de densidade da água. Nesta atividade, foram utilizados dois ovos, dois copos, sal e água, conforme as fotos a seguir:

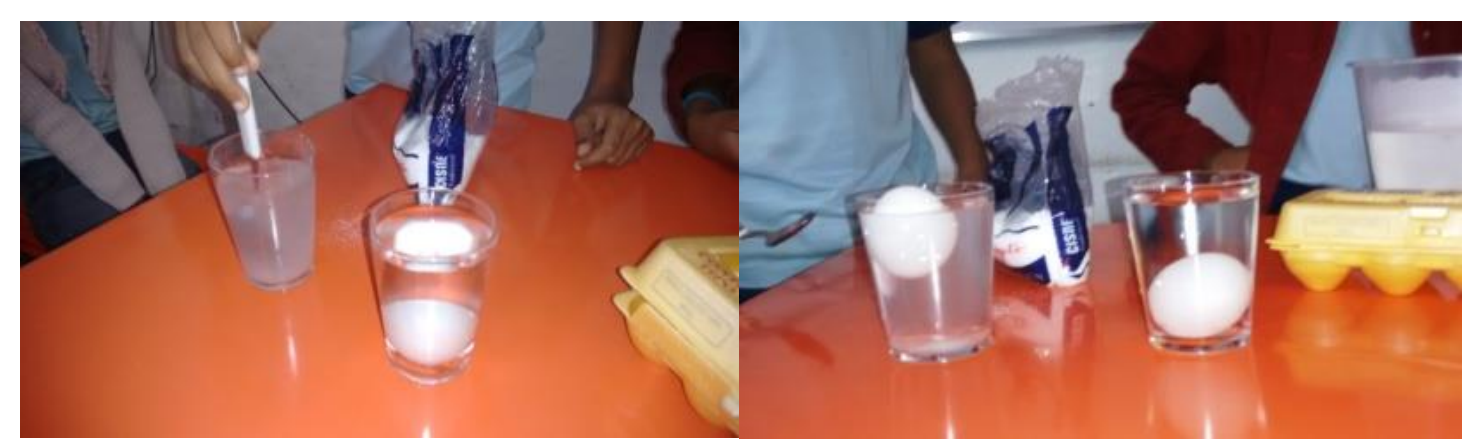

Figura 1. Imagens da experiência desenvolvida com os alunos do $5^{\circ}$ ano sobre densidade da água. Fonte: autoria nossa.

A partir da observação, os estudantes deveriam levantar hipóteses, analisar fatos, acionar o pensamento crítico durante a leitura dos textos informativos e científicos no Impress, escrevendo hipóteses neste referido software, em duplas, como nos exemplos a seguir.

\footnotetext{
${ }^{9}$ Disponível no Youtube: https://www.youtube.com/watch?v=RpuWT8fBxSI
} 


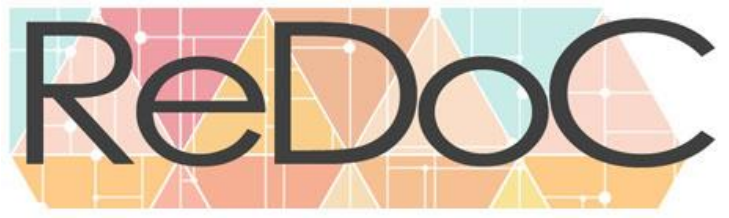

Revista Docência e Cibercultura
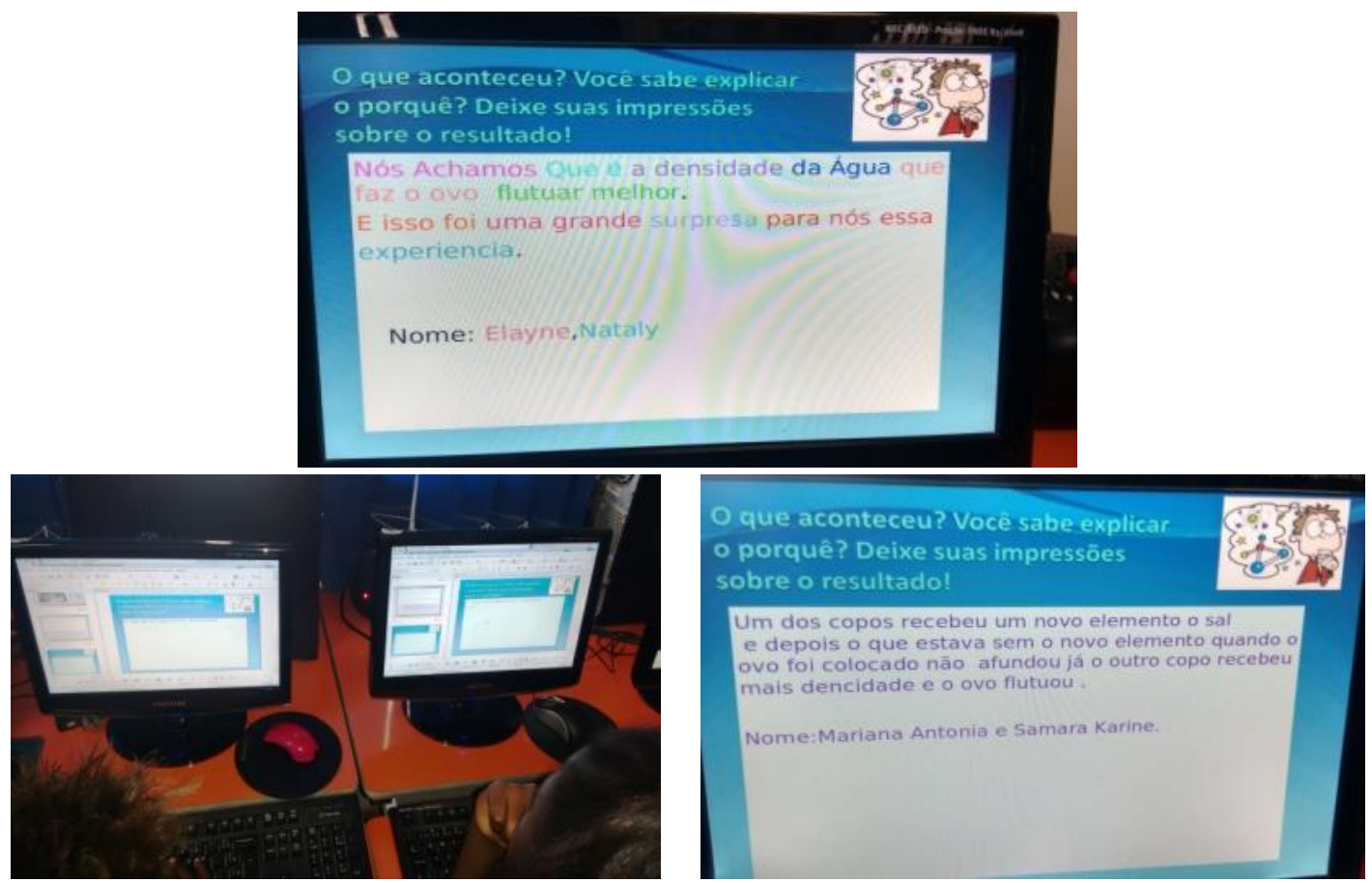

Figura 2. Imagens com produção dos estudantes no jogo do impress. Fonte: autoria nossa.

A professora mediadora de tecnologias construiu no Impress desafios de leitura de textos informativos e científicos por meio de jogos e propôs uma atividade de escrita em dupla. Outras propostas com jogos offline e recursos digitais foram desenvolvidas na turma de $4^{\circ}$ ano para trabalhar o mapa mundi e os continentes. O livro Lição de Geografia, de Ziraldo foi utilizado como $e$-book para começar as atividades.
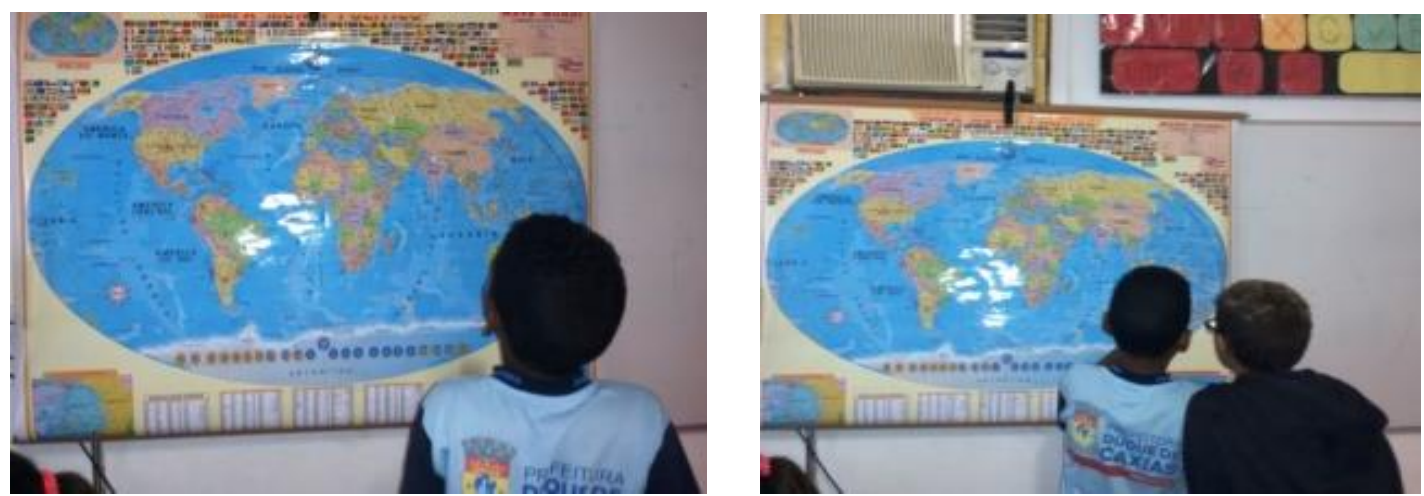

Figura 3. Mapa Mundi utilizados pelos estudantes do $4^{\circ}$ ano Fonte: autoria nossa. 


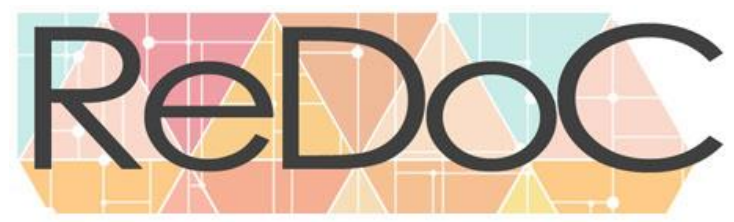

\section{Revista Docência e Cibercultura}

Cada dupla deveria ler o e-book e, depois, explorar o mapa mundi em material físico (cartaz) e em formato digital (computador) para identificar os continentes, ampliando, assim, o conhecimento cartográfico. Em seguida, realizariam atividades com o jogo do Jclic, consultariam o mapa, além de outros jogos offline sobre mapas e continentes.
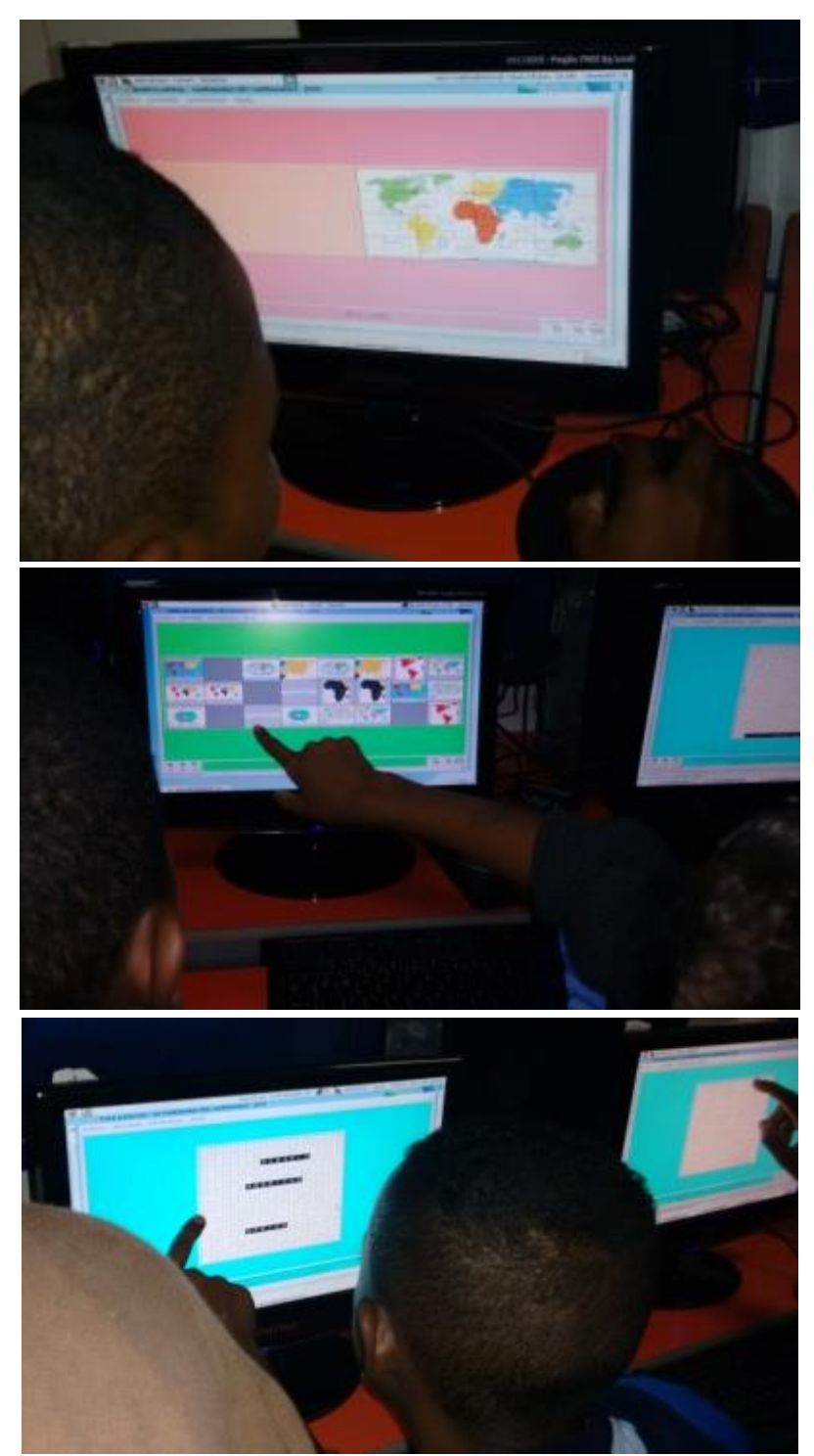

Figura 4. Atividades do Jclic sobre continentes. Fonte: autoria nossa.

O Jclic é uma ferramenta bastante utilizada por ser de fácil adoção. Com ele, é possível produzir quebra-cabeça, caça-palavras, jogo da memória, cruzadinha, entre outras atividades de leitura e escrita, por meio do lúdico. Além do Jclic, os estudantes também utilizaram jogo offline sobre o tema. 


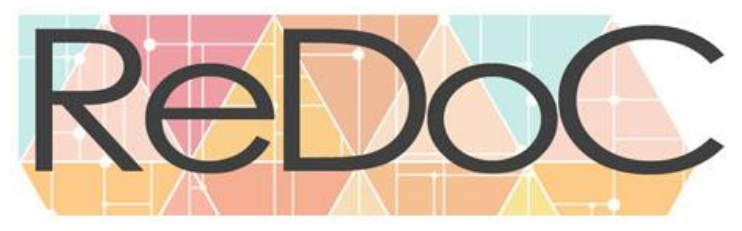

\section{Revista Docência e Cibercultura}

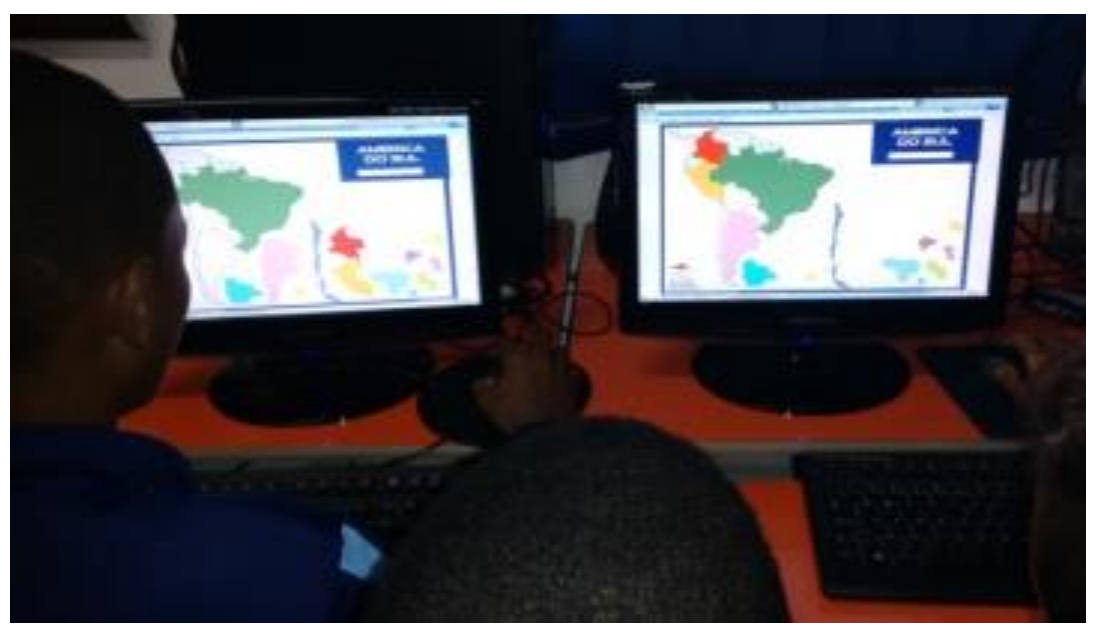

Figura 5. Exemplo de jogo off-line sobre continentes.

Fonte: autoria nossa.

As atividades exemplificadas foram desenvolvidas pela professora mediadora de tecnologias educacionais a partir da indicação do conteúdo pelo professor regente de cada turma. Entendemos que competência pedagógica, técnica, criativa, entre outras, são necessárias para a construção de jogos interessantes e desafiadores para estudantes de diferentes idades. A formação inicial e continuada de professores, portanto, precisa contemplar tais aspectos.

Por fim, a partir dos embasamentos teóricos e da prática com games, entendemos que os jogos despertam o interesse e promovem uma prática ativa por parte dos estudantes. Uma prática com gamificação, atrelada ao desenvolvimento de um projeto, potencializa a aprendizagem.

\section{Gamificação na formação inicial de professores}

O presente relato retrata uma prática que vem sendo aperfeiçoada a cada semestre letivo do curso de Pedagogia do Instituto Superior de Educação do Rio de Janeiro (ISERJ) ${ }^{10}$. A proposta foi implementada em duas turmas da disciplina "Informática Educativa" (disciplina ofertada no $1^{\circ}$ período), nos turnos da manhã e noite e foi realizada em três fases:

\footnotetext{
${ }^{10}$ O ISERJ foi, inicialmente, a Escola Normal da Corte. Em 1808, foi inaugurado e, somente em 1930, a Escola de Formação de Professores - Instituto de Educação - ganhava o seu prédio próprio, localizado até os dias atuais na Rua Mariz e Barros, entre Tijuca e Praça da Bandeira.
} 


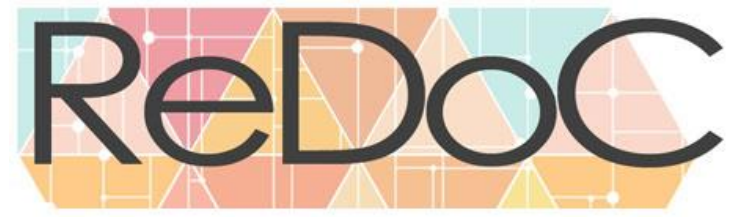

Revista Docência e Cibercultura

$1^{a}$ Discussão fundamentada na literatura, sobre jogos, softwares educacionais e seu potencial para educação;

$2^{\mathrm{a}}$ Oficina de produção de jogos offline, com o software de edição de apresentação e uma oficina de produção de quadrinhos, com a versão gratuita do site Pixton ${ }^{11}$;

$3^{\text {a }}$ Apresentação das produções para a turma, discorrendo sobre o planejamento onde se inseriria a atividade e o motivo de tal escolha.

Neste relato, a ênfase se concentra na segunda e terceira fases para melhor ilustrar a realização das produções autorais propostas. Após as discussões ocorridas com os alunos, no início do semestre de 2018-1, iniciaram-se as oficinas com proposições de atividades ou projetos, que, mais adiante, os alunos deveriam também implementar como parte da avaliação da disciplina.

A professora da disciplina informática educativa realizou a oficina de produção de jogos, usando o software proprietário da Microsoft, o PowerPoint, que é o editor de apresentações disponível no laboratório de informática do Ensino Superior. Ao adotar tal software para a produção de jogos ${ }^{12}$, a intenção é preparar o futuro professor para lidar com a mediação didática criativa sem a necessidade de acesso à Internet, situação de muitos laboratórios de informática das escolas públicas brasileiras. A oficina ocorreu em duas horas, que é o tempo semanal da aula, e algumas dúvidas decorrentes da proposta puderam ser sanadas nas demais aulas, antes da apresentação dos grupos. Também foi disponibilizado na sala virtual da turma, no Google Classroom, um tutorial ${ }^{13}$ para apoiá-los na produção e recordá-los da técnica apresentada na referida oficina.

A oficina de produção de quadrinhos on-line foi implementada por uma aluna do curso, que, na época, ${ }^{14}$ intencionava apresentar a pesquisa-formação de futuros professores para adoção de tecnologias na educação, como parte do seu trabalho de conclusão de curso (TCC). Sua oficina também teve duração de duas horas e contou com a disponibilização de um tutorial ${ }^{15}$ para auxiliar os licenciandos em suas produções de quadrinhos elaborado por esta aluna.

\footnotetext{
${ }^{11}$ Disponível em: https://www.pixton.com/br/.

${ }_{12}$ Os jogos produzidos pelas turmas estão reunidos no seguinte site: http://keitemelo.wixsite.com/recursoseducacionais/jogos

${ }^{13}$ Disponível em: https://youtu.be/AajapREMPV8.

${ }^{14}$ Posteriormente, a aluna optou por outro percurso metodológico e defendeu o seu TCC em outubro de 2019 , com o tema sistema de tutores inteligentes e personalização da aprendizagem.

${ }^{15} \mathrm{O}$ tutorial para produção de quadrinhos foi produzido pela ex-aluna do curso, Valéria Ribeiro Rodrigues, e pode ser acessado em: http://iserj.net/ava/mod/folder/view.php?id=746
} 


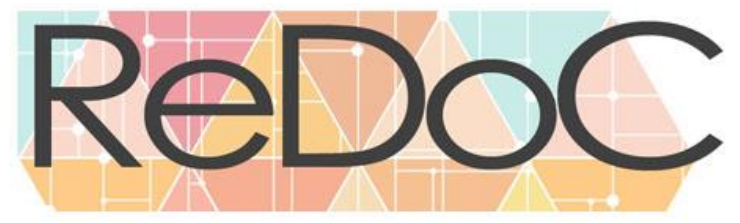

Revista Docência e Cibercultura

As produções (quadrinhos e jogos) foram realizadas em grupos de até quatro integrantes e, no final do semestre, foram apresentadas para a turma, com a participação da aluna do curso que implementou a oficina de quadrinhos como observadora das apresentações. Para a turma da noite, o tema dos quadrinhos ${ }^{16}$ era livre, mas, para a turma da manhã, havia o desafio de incorporar a temática de um dos textos propostos no planejamento em uma das atividades. Foi interessante perceber que, mesmo na turma da noite, alguns grupos optaram por incorporar o conteúdo ou demais problematizações pertinentes à disciplina nas atividades sem que esta sugestão estivesse anunciada. Os temas surgidos com as produções dos quadrinhos foram classificados da seguinte forma: natureza, lúdico na educação com tecnologias, isolamento social, museu, visibilidade nas redes sociais, bullying, igualdade de direitos, entre outros.

As produções dos licenciandos no formato de jogos produzidos com PowerPoint, em sua maioria, tinham o formato de quiz e se dedicavam a temas das disciplinas dos anos iniciais do Ensino Fundamental. A seguir, dois exemplos de jogos produzidos pelos alunos: um quiz sobre matemática em libras e um jogo da memória:

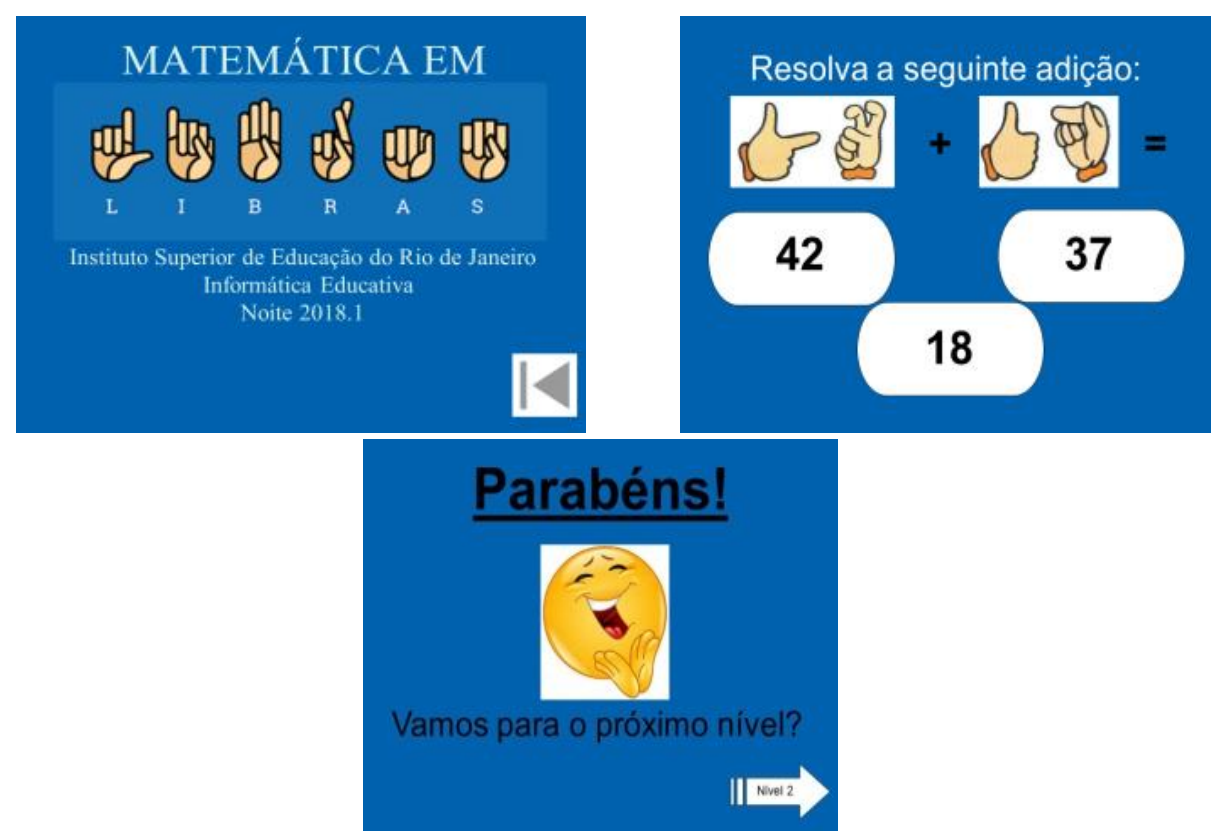

Figura 6. Três telas de um quiz produzido por um grupo, da turma da noite. Fonte: autoria nossa.

\footnotetext{
${ }^{16}$ Alguns quadrinhos podem ser acessados no seguinte link: https://Pixton.com / e, após a barra, neste endereço, os seguintes códigos podem ser acrescentados para visualizar distintos quadrinhos: hq:bj37g4ms, hq:cx9nyyoh, bgfwlcn6, br/comic-strip/b8vpujwh, hq:d9bv6xix, hq:ap1b621k, hq:9z1sxxf9, hq:i5cp4i7u, ic:xjsdq4ww, hq:kygc3nx4 e hq:yh5v8blb.
} 


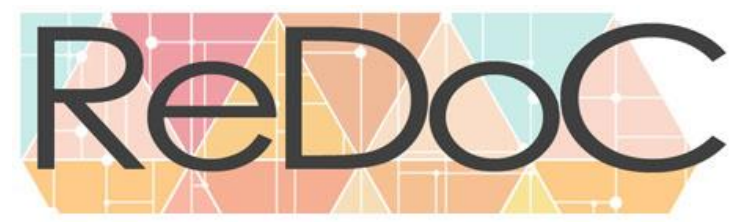

Revista Docência e Cibercultura
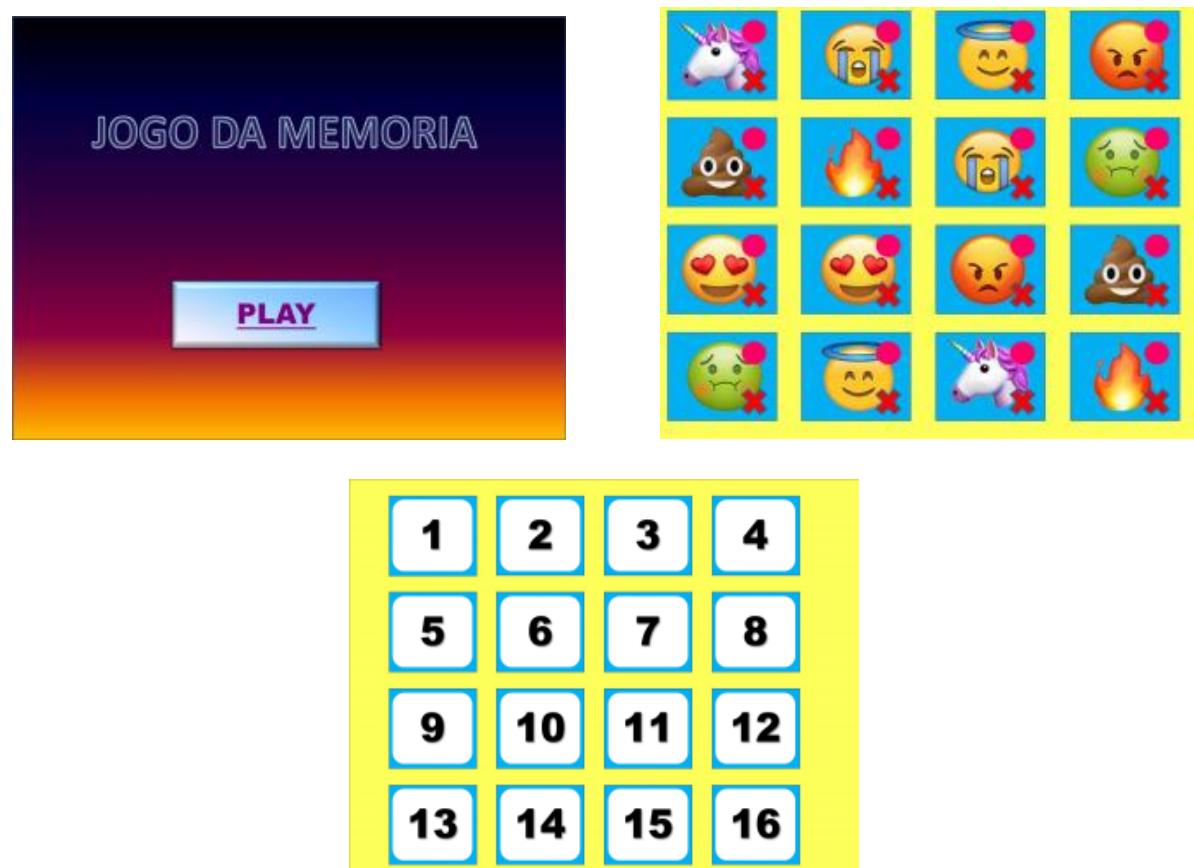

Figura 7. Três telas de jogo da memória produzido por um grupo, da turma da manhã. Fonte: autoria nossa.

Na escolha pela produção de um jogo da memória, entendemos que houve uma maior apropriação, fruto da autonomia discente e envolvimento com a proposta. A oficina implementada pela professora apenas exemplificou a produção de jogos no formato de quiz e o grupo produziu um formato distinto, apresentando outra apropriação da tecnologia. É possível compreender que houve uma conciliação da atividade com o prazer próprio da produção com a ludicidade, potencializando a liberdade de autoria e objetivação, o que seria o objetivo deste tipo de proposta de mediação didática.

\section{CONSIDERAÇÕES FINAIS}

As relações mediadas pelas tecnologias vêm se intensificando e trazendo, cada vez mais, imersão dos sujeitos na cultura digital. Uma interface da cultura digital, que sempre foi um grande atrativo para os mais jovens, graças às atividades lúdicas e interativas, atualmente ganha maior destaque graças ao potencial da mobilidade: estamos falando dos jogos. Os jogos costumam ser atrativos para qualquer faixa etária, mas, quando atrelados à tecnologia, o interesse aumenta, além de potencializar a ubiquidade (acesso a qualquer momento e em qualquer lugar). $\mathrm{O}$ crescimento do interesse nos jogos digitais pode ser justificado pelo advento da cultura digital, que vem modificando comportamentos individuais, sociais e 


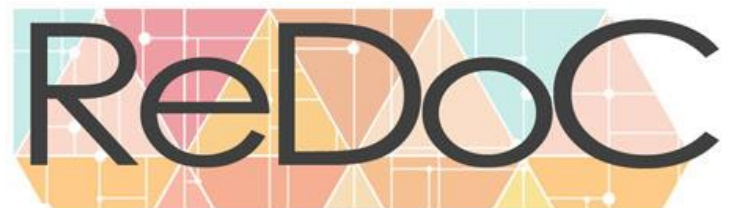

Revista Docência e Cibercultura

educacionais, entre outros. Portanto, a escola precisa repensar suas práticas didáticas e metodológicas.

Acreditamos que a ludicidade mobiliza os sujeitos, engajando-os em atividades que demandam maior capacidade de abstração e desafios complexos, que, de outra forma, poderiam não ter a mesma adesão e compreensão. Apesar disso, reconhecemos que um entrave bastante comum nas escolas públicas é a dificuldade de acesso à Internet, embora esse não seja um fator limitador para uma prática com jogos, como apresentamos nos dois relatos deste trabalho. A maior parte dos jogos produzidos nos referidos relatos foi desenvolvida sem a necessidade de acesso à rede, mas isso não significa que não haja necessidade de se denunciar a exclusão digital vivenciada pelas escolas, principalmente por estarmos vivendo uma era da mobilidade e crescente ubiquidade.

As mediações didáticas docentes atuam pedagogicamente dentro e fora de salas de aula. Esta atuação possui por desafio conciliar os recursos disponíveis ao potencial criativo ao mesmo tempo em que não se acomoda com a escassez ou outras restrições, como, por exemplo, a ausência de manutenção (PISCHETOLA; MIRANDA, 2019). A mediação didática também adota a criatividade em potência para acessar estratégias de resistência e luta, com o fim de contribuir com o real acesso à cidadania e inclusão social.

Buscamos com os presentes relatos de experiências desenvolvidos por e com alunos em instituições públicas, que atravessam tempos difíceis, estimular a potência criativa dos docentes. Esperamos inspirar ações e formações para a adoção do lúdico na educação, reconhecendo o potencial das tecnologias offline e as TDIC.

\section{REFERÊNCIAS}

CABRERA, Waldirléia Baragatti; SALVI, Rosana. A ludicidade no Ensino Médio: Aspirações de Pesquisa numa perspectiva construtivismo. In: Atas do V Encontro Nacional de Pesquisa em Educação em Ciências, Associação Brasileira de Pesquisa em Educação em Ciências. n. 5, pp. 1-11, Bauru, 2005. Disponível em: <http://www.nutes.ufrj.br/abrapec/venpec/conteudo/artigos/1/pdf/p65.pdf>. Acesso em: 01 jul. 2019.

CARVALHO, Ana Amélia Amorim. Jogos digitais e gamification: desafios e competição para aprender na era mobile learning. In: CONSELHO NACIONAL DE EDUCAÇÃO. Aprendizagem, TIC e Redes Digitais [Textos do Seminário realizado no CNE a 6 de abril de 2016]. Ercília Faria e Rute Perdigão (Orgs. Ed.), 2017. Disponível em: $\langle$ http://www.cnedu.pt/content/edicoes/seminarios_e_coloquios/LIVRO_TIC_RedesDigitais.pdf $>$. 


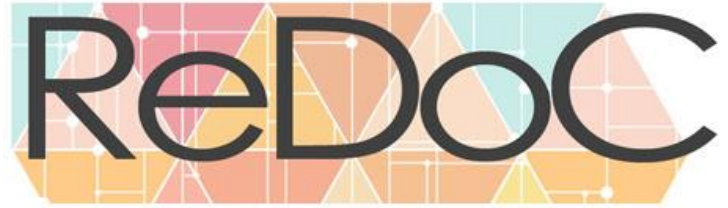

Acesso

em

Revista Docência e Cibercuttura

CETIC.BR. Principais Resultados. TIC Educação 2017. São Paulo: CGI.br - Comitê Gestor da Internet no Brasil. NIC.br - Núcleo de Informação e Coordenação do Ponto BR. Cetic.br - Centro Regional de Estudos para o Desenvolvimento da Sociedade da Informação, 2018. Disponível em: <https://cetic.br/media/analises/tic_educacao_2017_coletiva_de_imprensa.pdf $>$. A acesso em 03 jul. 2019.

CRUZ, Giuliano César da; CASTRO, Adriane Belluci Belório de. Utilização de Jogos Digitais Educativos no Ensino Médio Público em Botucatu-SP. In: Simpósio Internacional de Educação à distância e Encontro de pesquisadores em Educação à Distância, pp. 1-6, Universidade Federal de São Carlos, São Carlos/SP, Set. 2014.

FACCI, Marilda Gonçalves Dias. A periodização do desenvolvimento psicológico individual na perspectiva de Leontiev, Elkonin e Vigostski. Cad. Cedes, Campinas, vol. 24, n. 62, p. 64-81, abril 2004. Disponível em: 〈http://www.scielo.br/pdf/ccedes/v24n62/20092.pdf〉. Acesso em 17 mai. 2019.

FALKEMBACH, Gilse Antoninha Morgental; GELLER, Marlise; SILVEIRA, Sidnei Renato. Desenvolvimento de Jogos Educativos Digitais utilizando a Ferramenta de Autoria Multimídia: um estudo de caso com o ToolBook Instructor", Revista Novas Tecnologias na Educação/ CINTED-UFRGS, v. 4, n. 1, Jul. 2006. Disponível em: <http://www.seer.ufrgs.br/renote/article/viewFile/13874/7794>. Acesso em: 01 jul. 2019.

GADOTTI, Moacir. História das ideias pedagógicas. 2ª.ed. São Paulo: Ática, 2000.

HUIZINGA, Johan. (2000). Homo Ludens. $4^{\text {a }}$ ed. São Paulo: Editora Perspectiva, 2000.

LEONTIEV, Alexis N. Atividade Consciência e Personalidade. 1978. Disponível em: 〈http://www.dominiopublico.gov.br/download/texto/ma000004.pdf >.

Acesso em 31 mar. 2019.

. O desenvolvimento do psiquismo. 2. ed. São Paulo: Centauro, 2004.

LÉVY, Pierre. As tecnologias da inteligência: o futuro do pensamento na era da informática. Editora 34, 1993.

LIBÂNEO, José Carlos. ANTINOMIAS NA FORMAÇÃO DE PROFESSORES E A BUSCA DE INTEGRAÇÃO ENTRE O CONHECIMENTO PEDAGÓGICO-DIDÁTICO E O CONHECIMENTO DISCIPLINAR. In: MARIN, Alda Junqueira; PIMENTA, Selma Garrido (orgs.). Didática: teoria e pesquisa. 2. ed. - Araraquara,SP: Junqueira\&Marin; Ceará: UECE, 2018.

MATOS, Santer Alvares; SHAYER, Cláudia de Vilhena Shayer; GIUSTA, Agnela da Silva. Jogo dos Quatis: Uma Proposta de uso do jogo no Ensino de Ecologia. Ciência em Tela: Rede de 


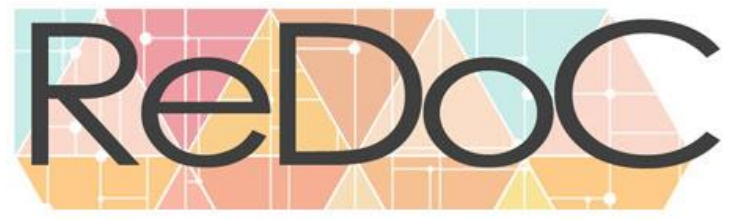

Revista Docência e Cibercultura

Investigação, Divulgação e Educação em Ciências/UFRJ. v. 3, n. 2, pp. 1-15, 2010. Disponível em: <http://www.cienciaemtela.nutes.ufrj.br/artigos/0210_matos.pdf >. Acesso em: 01 jul. 2019.

MELO, Keite Silva de; OLIVEIRA, Gabriella Portela Barbosa de. Adoção do app Kahoot para e na Avaliação: Uma experiência na formação inicial de professores. Democratizar, v. XI, n. 1, jan./jun. 2018. Disponível em: <http://www.faeterjpetropolis.edu.br/democratizar/index.php/dmc/issue/viewFile/v.\%2011\%2C\%20n.\%201\%20\%28 2018\%29/163>. Acesso em 03 jul. 2019.

NASCIMENTO, Carolina Picchtetti; ARAÚJO, Elaine Sampaio; MIGUEIS, Marlene da Rocha. O conteúdo e a estrutura da atividade de ensino na educação infantil: o papel do jogo. In: MOURA, Manoel Oriosvaldo (org.). A atividade pedagógica na teoria histórico-cultural. $2^{\mathrm{a}}$ ed. Campinas, SP: Autores Associados, 2016.

NÓVOA, António. Os professores na virada do milênio: do excesso dos discursos à pobreza das práticas. Educação e Pesquisa, São Paulo, v. 25, n. 1, p. 11-20, jan./jun. 1999. Disponível em: <http://www.scielo.br/pdf/ep/v25n1/v25n1a02.pdf>. Acesso em: 13 jul. 2019.

OLIVEIRA, Artur Bruno Fonseca de; LIMA, Ana Ignez Belém. Vigostki e os processos criativos de professores ante a realidade atual. Educação \& Realidade. v. 42, n. 4, 2017. Disponível em: ,http://www.scielo.br/scielo.php?pid=S2175-62362017005005101\&script=sci_abstract\&tlng=pt $>$. Acesso em 07 jul. 2019.

PISCHETOLA, Magda; MIRANDA, Lyana Thédiga de. A sala de aula como ecossistema: tecnologias, complexidade e novos olhares para a educação. Rio de Janeiro: Ed. PUC-Rio, 2019.

PROVEnZANO, Maria Esther; WALDHELM, Mônica. Didática. Módulo 4 do Curso de Especialização em Educação Tecnológica. Rio de Janeiro: CEFET/RJ, 2009.

SACRISTÁN, J. Gimeno. Consciência e acção sobre a prática como libertação profissional dos professores. In: NÓVOA, António (org.). Profissão Professor. $2^{\mathrm{a}}$ edição. Porto: Porto Editora, 1995.

SANTAELLA, Lucia. Comunicação ubíqua: repercussões na cultura e na educação. São Paulo: Paulus, 2013. Edição do Kindle.

SANTOS, Élia Amaral do Carmo. O Lúdico no Processo Ensino-Aprendizagem. Dissertação (Mestrado em Ciências da Educação), Universidad Tecnológica Intercontinental/UTIC. Asunción, Paraguay, 2010. Disponível em: 〈http://need.unemat.br/4_forum/artigos/elia.pdf>. Acesso em: 01 jul. 2019.

VALENTE, José Armando. Computadores e conhecimento: repensando a educação. Campinas: UNICAMP. 1993.

VYGOTSKY, L. S. A formação social da mente: o desenvolvimento dos processos psicológicos superiores. São Paulo: Martins Fontes, 2003. 